\title{
Sugammadex as rescue therapy for residual neuromuscular blockade in the intensive care unit
}

\author{
Michele Carron, MD, PhD · Fabio Baratto, MD • Tommaso Pettenuzzo, MD • \\ Carlo Ori, MD
}

Received: 12 August 2016/Revised: 17 August 2016/Accepted: 1 September 2016/Published online: 19 September 2016

(C) Canadian Anesthesiologists' Society 2016

\section{To the Editor,}

We read with interest the paper by Roy et al. about a case of awake paralysis in the intensive care unit (ICU) due to residual neuromuscular blockade (NMB) in a patient who had undergone fast-track cardiac surgery. ${ }^{1}$ Complete recovery from NMB before tracheal extubation may avoid complications related to postoperative residual NMB, including the patient's awareness of this unpleasant condition. ${ }^{1}$ The authors pointed out that the risk of postoperative residual NMB could be minimized by routinely assessing neuromuscular function before cessation of sedation. ${ }^{1}$ However, quantitative neuromuscular function monitoring does not entirely abolish the risk of postoperative residual $\mathrm{NMB}^{2}$ In some situations (e.g., malfunction, absence of calibration and normalization, peripheral neuropathy, hypothermia), monitoring may be not able to predict accurately an adequate recovery from $\mathrm{NMB}^{2}$ Furthermore, it is not always used in clinical practice. ${ }^{1,2}$ Rujirojindakul et al. found that, despite the use of traditional NMB-reversal agents and meeting the standard criteria for extubation, administration of either benzylisoquinolines (odds

Editor's Note The authors of the article: Can J Anesth 2016; 63: 725-30, respectfully declined an invitation to submit a reply to the above letter.

M. Carron, MD, PhD $(\bowtie) \cdot$ F. Baratto, MD .

T. Pettenuzzo, MD - C. Ori, MD

Department of Medicine, Anesthesiology and Intensive Care,

University of Padova, Padova, Italy

e-mail: michele.carron@unipd.it ratio $[\mathrm{OR}], 3.9 ; 95 \%$ confidence interval [CI] 1.46 to 10.3 ) or aminosteroid derivatives (OR, 7.6; 95\% CI, 2.7 to 19.8) as an intraoperative neuromuscular blocking agent is an independent risk factor for reintubation in the post-anesthetic care unit. ${ }^{3}$

Symptomatic postoperative residual NMB, particularly if associated with critical respiratory events (CREs), needs prompt treatment. ${ }^{2}$ If available, sugammadex should be carefully considered after aminosteroid-induced NMB. Compared to neostigmine, sugammadex can reverse NMB more rapidly and allows prompt treatment of CRE associated with postoperative residual NMB, avoiding the need for prolonged sedation or reintubation., ${ }^{2,4}$ Furthermore, sugammadex reverses NMB with a lower likelihood of postoperative weakness (OR, 0.45; 95\% CI, 0.21 to 0.97$)$ or adverse respiratory (OR, 0.36 ; $95 \% \mathrm{CI}$, 0.14 to 0.95 ) and cardiovascular (OR, $0.23 ; 95 \% \mathrm{CI}, 0.08$ to 0.61 ) events. ${ }^{4}$ On the contrary, reversal of NMB with neostigmine, particularly if administered in an inadequate dose or without appropriate guidance from neuromuscular function monitoring, has been associated with an increased risk of postoperative desaturation $<90 \%$ (OR, 1.32, 95\% $\mathrm{CI}, 1.20$ to 1.46$)$ and reintubation (OR, $1.76 ; 95 \% \mathrm{CI}, 1.38$ to 2.3)..$^{5}$ Neostigmine and qualitative monitoring of neuromuscular function, often used in the ICU to assess recovery from NMB, seem not to mitigate the increased risk of postoperative CREs linked to the use of nondepolarizing neuromuscular blocking agents. ${ }^{5}$

In their conclusions, Roy et al. rightly underlined the importance of new solutions, in addition to those readily available, to minimize the consequences of postoperative residual NMB in the ICU. ${ }^{1}$ We believe that sugammadex, which has been proven an effective rescue therapy to reverse NMB, should be included in strategies used to prevent postoperative residual NMB and associated CREs in the ICU whenever possible. 
Interest disclosure Michele Carron, Fabio Baratto and Carlo Ori have received payments for lectures from Merck Sharp \& Dohme (MSD), Italy. Tommaso Pettenuzzo has no interests to disclose.

Editorial responsibility This submission was handled by Dr. Hilary P. Grocott, Editor-in-Chief, Canadian Journal of Anesthesia.

\section{References}

1. Roy M, Morissette N, Girard M, Robillard N, Beaulieu P. Postoperative awake paralysis in the intensive care unit after cardiac surgery due to residual neuromuscular blockade: a case report and prospective observational study. Can J Anesth 2016; 63: 725-30.
2. Carron M, Baratto F, Zarantonello F, Ori $C$. Sugammadex for reversal of neuromuscular blockade: a retrospective analysis of clinical outcomes and cost-effectiveness in a single center. Clinicoecon Outcomes Res 2016; 8: 43-52.

3. Rujirojindakul P, Geater AF, McNeil EB, et al. Risk factors for reintubation in the post-anaesthetic care unit: a case-control study. Br J Anaesth 2012; 109: 636-42.

4. Carron M, Zarantonello $F$, Tellaroli $P$, Ori $C$. Efficacy and safety of sugammadex compared to neostigmine for reversal of neuromuscular blockade: a meta-analysis of randomized controlled trials. J Clin Anesth 2016; 35: 1-12.

5. Grosse-Sundrup M, Henneman JP, Sandberg WS, et al. Intermediate acting non-depolarizing neuromuscular blocking agents and risk of postoperative respiratory complications: prospective propensity score matched cohort study. BMJ 2012; 345: e6329. 